\title{
UM PANORAMA DAS PESQUISAS SOBRE LIVRO DIDÁTICO E EDUCAÇÃO AMBIENTAL
}

\section{Environmental education research in textbooks: an overview}

\author{
Natália Salan Marpica ${ }^{1}$ \\ Amadeu José Montagnini Logarezzi²
}

Resumo: Ao considerarmos a educação ambiental de forma permanente e cotidiana nas escolas, verificamos que o livro didático participa deste processo de modo bastante significativo, dada sua importância no ensino e na aprendizagem vivenciados por docentes e discentes. Este artigo tem como objetivo levantar as pesquisas realizadas envolvendo livro didático e educação ambiental, para conhecimento do que vem sendo produzido sobre o assunto e de quais os principais desafios à pesquisa neste segmento. As pesquisas levantadas apontaram várias deficiências encontradas nos livros didáticos como instrumento de apoio à abordagem da educação ambiental no contexto escolar. No entanto, verificamos que o conjunto dessas pesquisas apresenta lacunas em sua potencial contribuição para a melhoria dos livros didáticos como ferramenta que propicie a incorporação da dimensão ambiental no processo de ensino e aprendizagem.

Palavras-chave: Educação ambiental. Livro didático. Estado da arte.

Abstract: When we consider environmental education and its effect in the daily schools activities, we can note that the textbook participates in this process in a very significant way, due to its importance in the defining the educational content and in the learning experienced by the teachers and the pupils. The objective of the present article is to survey studies related to the research undertaken involving textbooks and environmental education in order to communicate what is being done regarding the subject, identifying the main challenges. The research shows several deficiencies encountered in the textbook as instrument of support to environmental educational approaches in the school context. However, we have found that the set research studied presents some gaps in its potential contribution towards the enhancement of the textbooks as tools for providing the incorporation of environmental dimensions into the learning process.

Keywords: Environmental education. Textbook. State of art.

\footnotetext{
${ }^{1}$ Tecnológa em Saneamento Ambiental. Mestre em Educação. Mestranda em Comunicación com fines sociales, Facultad de Ciencias Sociales, Jurídicas y de la Comunicación, Universidad de Valladolid (UVA). Segovia, Espanha.<nataliasalan@yahoo.com.br>

${ }^{2}$ Engenheiro de Materiais. Doutor em Ciências Físico-Químicas. Docente, Departamento de Engenharia de Materiais, Universidade Federal de São Carlos, SP, Brasil. <amadeu@ufscar.br>

${ }^{1}$ Rua do Sacramento, 615,

São Bernardo do Campo, SP

09.635-120 
Marpica, N. S.; Logarezzi, A. J. M.

\section{Introdução}

A educação, particularmente nas práticas pedagógicas escolares, pode ser vista como um processo importante para transformações da realidade que conduzam a um mundo socialmente mais justo e ambientalmente mais sustentável. Para tanto, entre as escolhas que devem marcar o trabalho escolar, destaca-se a necessidade, cada vez mais imperativa, de incorporação da dimensão ambiental em suas práticas, especialmente no processo de ensino e aprendizagem. Nesse sentido, diferentes elementos interferem nessa incorporação, como: as políticas públicas para o setor, o projeto político pedagógico da unidade escolar, a gestão escolar, os conhecimentos, a experiência e o comprometimento do(a) professor(a), a estrutura física e os recursos da escola, a organização dos espaços e dos tempos das atividades, o contexto sociocultural dos estudantes, o livro didático e outros.

Entre esses elementos, as políticas em educação são disposições que implicam todos os demais, repercutindo no resultado do ensino em geral. Destacam-se os Parâmetros Curriculares Nacionais (PCN) e a Política Nacional de Educação Ambiental (PNEA), instituída pela Lei 9.795/1999 (BRASIL, 1999), ambas propondo que a educação ambiental deva ter um caráter transversal na escola, não constituindo uma disciplina, mas permeando todas as já existentes (BRASIL, 1997).

Neste cenário, o livro didático cumpre um papel de grande importância. Na medida em que é um elemento que está presente em sala de aula, auxilia a implementação das políticas de educação em geral e a abordagem da educação ambiental em âmbito formal. O livro didático apoia o planejamento das atividades de ensino e fundamenta o seu desdobramento em aprendizagem, no processo pedagógico desenvolvido por professor(a) e estudantes. Ainda, ao considerarmos que a incorporação da dimensão ambiental não deve ser implementada por meio de uma disciplina no currículo escolar, o livro didático surge também como um potencial promotor da transversalidade necessária para tratar uma temática complexa como é a questão ambiental na atualidade, sobretudo quando vista da perspectiva de uma educação ambiental problematizadora, crítica e transformadora, ou seja, que encara a questão ambiental atrelada às questões sociais, culturais, éticas e ideológicas, conforme descrevem vários autores desse campo, como Carvalho (2004), Loureiro (2006), Tozoni-Reis (2004), Sorrentino et al. (2005), Guimarães (2004) e outros.

Este artigo ${ }^{3}$ tem como objetivo geral conhecer e discutir a produção acadêmica relativa à educação ambiental nos livros didáticos. Isto implica levantar as pesquisas que envolvem a educação ambiental e os livros didáticos realizadas até o momento e analisar como se configura este campo de investigação. Buscar esse conhecimento e promover essa discussão significa: (a) organizar as pesquisas deste campo, que ainda estão bastante dispersas; (b) entender o que se conhece sobre o tema; (c) identificar os desafios e as perspectivas para a constru-

${ }^{3}$ Elaborado com base em Marpica (2008), dissertação de mestrado que contou com financiamento da Capes. 
Um panorama das pesquisas sobre livro didático ...

ção do livro didático como uma ferramenta de apoio à incorporação da dimensão ambiental no contexto escolar e, por fim, (d) abrir possibilidades de novas pesquisas que possam contribuir para a elaboração de livros e materiais didáticos comprometidos com a incorporação da temática ambiental.

\section{Caminhos teórico-metodológicos}

No levantamento dos dados para esta discussão, foram utilizadas três fontes de pesquisa e o critério para selecionar os trabalhos foi a abordagem explícita da educação ambiental e de livro didático. Buscamos informações no banco de dissertações e teses da Coordenação de Aperfeiçoamento de Pessoal de Nível Superior (Capes), nos anais das quatro primeiras edições do Encontro de Pesquisa em Educação Ambiental (EPEA), na publicação "Avaliando a educação ambiental no Brasil: materiais impressos" e em outras fontes que não estão organizadas em espaço único: são teses, livros e artigos que foram sendo reunidos conforme encontrados em bibliotecas e periódicos. O banco da Capes foi considerado relevante por reunir dissertações e teses de programas de todo o Brasil e de diversas áreas do conhecimento, defendidas até 2007. Por sua vez, o EPEA vem cumprindo, desde 2001, importante papel na consolidação do campo da educação ambiental no Brasil, contribuindo especificamente para a melhoria da qualidade dos trabalhos de pesquisa, além de se constituir em um fórum onde se encontram trabalhos de diferentes regiões do país e de diferentes temáticas e bases teóricas. A relevância da referida publicação sobre materiais impressos decorre do fato de que aquela avaliação se baseia em um banco que reúne oitocentos e oitenta publicações de diversas naturezas em educação ambiental, incluindo livros didáticos, publicadas até 1996. Por fim, as fontes dispersas consultadas possibilitaram a obtenção de dados complementares e de revisões que contribuíram para a construção de um panorama mais abrangente do objeto desta pesquisa. Destaca-se que apenas foram consultadas fontes que fazem menções específicas à educação ambiental, excluindo-se da busca fontes que focalizam apenas livros didáticos, independentemente da disciplina a que se referem, pois pautamos a pesquisa na orientação do PCN e da PNEA, que reitera o caráter transversal da educação ambiental.

Com o acervo a ser investigado em mãos, foram levantados, em cada trabalho: o objetivo, o referencial teórico-metodológico e os principais resultados e conclusões das pesquisas. Em alguns casos, tivemos acesso somente aos resumos, o que não permitiu que todas estas informações fossem coletadas.

$\mathrm{Na}$ coleta de trabalhos a serem submetidos à análise, não foi definido nenhum período, mas, ao todo, o conjunto investigado abrange 25 anos - de 1984 a 2008.

Os dados foram analisados a partir do olhar da educação ambiental crítica, que parte do princípio de que o ambiente é resultado de todo um contexto social, construído historicamente, num movimento permanente de transformações culturais, políticas e econômicas, entendendo-o não como algo isolado, mas como um fluxo movido por relações diversas (LOUREIRO, 2005). A análise foi realizada também com base na pedagogia freireana - que entende a realidade como resultado histórico da ação humana - e a mudança desta realidade, possível também pela ação humana, de forma permanente, cotidiana e reflexiva: 
Marpica, N. S.; Logarezzi, A. J. M.

A realidade social, objetiva, que não existe por acaso, mas como produto da ação dos homens também não se transforma por acaso. Se os homens são os produtores desta realidade e se esta, na 'inversão da práxis', se volta sobre eles e os condiciona, transformar a realidade opressora é tarefa histórica, é tarefa dos homens. (FREIRE, 1987, p. 37, grifos do autor)

A realidade como um processo histórico implica, no processo educativo, negar o sujeito "abstrato, isolado, solto, desligado do mundo, assim como também a negação do mundo como uma realidade ausente dos homens" (FREIRE, 1987, p. 70). Desta forma, os dados foram analisados entendendo-se que o processo de educação ambiental deve favorecer a contextualização do sujeito, imerso no mundo, como ser social e historicamente situado, em relações sociais concretas e diferenciadas, com responsabilidades sociais e ambientais também diferenciadas (LIMA, 2006).

\section{Dados coletados}

\section{Fonte: Banco de dissertações e teses da Capes}

No banco de dissertações e teses da Capes (http://www.periodicos.capes.br), a busca foi orientada pelas expressões "educação ambiental" e "livro didático", o que resultou em 32 aparições de trabalho. Contudo, ao lermos os resumos dos referidos trabalhos, verificamos que apenas dez utilizavam o livro didático como objeto de análise $e^{4}$.

Entre estes dez trabalhos, apenas um é de doutorado e todos os demais são de mestrado. Com relação ao local de realização das pesquisas, três são do estado de São Paulo, duas do Rio de Janeiro, duas da Paraíba, uma de Minas Gerais, uma do Paraná e uma do Mato Grosso do Sul, não havendo nenhum trabalho realizado na região norte do país.

Quanto às disciplinas às quais os livros didáticos analisados se remetiam, foram encontradas: três pesquisas referentes à disciplina de geografia, duas à de ciências, uma à de história, uma à de biologia, uma multidisciplinar (ciências, geografia, história e língua portuguesa) e duas pesquisas que não identificaram a disciplina dos livros didáticos analisados.

Das pesquisas verificadas, seis analisavam livros didáticos do Ensino Fundamental, duas do Ensino Médio, uma do Ensino Fundamental e Médio e uma sem identificação do ciclo escolar ao qual se refere.

Verifica-se também que duas das dez pesquisas realizadas utilizaram, como referencial teórico da educação ambiental, a vertente crítica, e duas se pautaram nas concepções do PCN sobre meio ambiente. As outras seis não identificaram os referenciais teóricos da educação ambiental que orientaram as pesquisas.

\footnotetext{
${ }^{4}$ Ressaltamos que, em alguns casos, tivemos acesso ao exemplar da dissertação ou tese original, mas em outros utilizamos as informações contidas nos resumos disponíveis no banco da Capes.
} 
Um panorama das pesquisas sobre livro didático ...

Os principais resultados debatidos nestas pesquisas apontam para o fato de que a questão ambiental está sendo abordada nos livros didáticos (RIBEIRO, 2006), contudo de forma ainda superficial. Por exemplo, apontaram que aspectos bióticos, abióticos e culturais estão presentes nos livros didáticos, mas de forma desarticulada e desconexa entre os mesmos, o que ressalta a presença das questões ambientais nos livros didáticos, mas com limitações de qualidade (BEZERRA, 2003). De forma geral, estas pesquisas levantaram muitas lacunas e incoerências nos livros didáticos quanto à abordagem das questões ambientais.

Quanto aos conceitos verificados nos livros didáticos, destacam, por exemplo, que o entendimento de desenvolvimento sustentável é pautado na eficiência e na lógica de mercado, com soluções de ordem tecnológica para a crise ambiental, desconsiderando a questão social do debate e restringindo a questão ambiental a um assunto da ecologia (COUTO, 2005). Já a concepção de natureza verificada pelas pesquisas nos livros didáticos é muitas vezes contraditória, pois ora se pauta numa visão antropocêntrica e utilitarista, em que a natureza é entendida apenas como um recurso à sociedade, ora se limita a elementos naturais do meio, excluindo-se o ser humano, ressaltando um caráter conservacionista da relação sociedade-ambiente, onde ser humano e natureza são antagônicos (RIBEIRO, 2006; SOARES, 2005; FRACALANZA, 1992).

Uma das críticas realizadas nas investigações refere-se ao caráter parcial da interdisciplinaridade da questão ambiental nos livros didáticos, na medida em que seu tratamento ainda é mais enfático nos livros de geografia e de ciências (GROSSI, 2004; BEZERRA, 2003).

Foi verificado também que não há uma aproximação com as questões ambientais de caráter local. Isto se deve, em grande parte, à centralização da produção dos livros didáticos na região sudeste do país, mas também à abordagem de questões de outros países e de imagens da realidade estrangeira (COUTO, 2005; SOARES, 2005; BEZERRA, 2003; PEGORARO, 1998).

Um outro elemento verificado refere-se à distribuição dos conteúdos ambientais ao longo das coleções e volumes de livros didáticos, a qual se apresentou, de acordo com as investigações, de forma descontínua e intermitente, não havendo uma regularidade dos conteúdos ambientais (RIBEIRO, 2006). Fracalanza (1992) ressalta que os conteúdos ambientais aparecem em capítulos específicos, após a abordagem de conceitos ecológicos, geralmente ao final do livro.

Quanto à abordagem atitudinal da prática educativa voltada ao ambiente, presente nos livros didáticos, são raras as propostas de atuação e, quando essas acontecem, apenas as atitudes pontuais e individuais de conservação de elementos da natureza são exaltadas (RIBEIRO, 2006) ou, ainda, propõem-se atividades relacionadas a realidades muito distantes, como problemas ambientais na China (SOARES, 2005). Neste sentido, Grossi (2004) conclui que os livros didáticos não utilizam os textos como um meio para se alcançarem transformações nas relações com o ambiente, mas que os conteúdos são um fim em si mesmos, consagrando a transmissão de informações para sua memorização.

\section{Fonte: EPEA}

Outra fonte de busca das pesquisas realizadas sobre educação ambiental e livros didáticos foram os anais das quatro primeiras edições do Encontro de Pesquisa em Educação 
Marpica, N. S.; Logarezzi, A. J. M.

Ambiental (EPEA) ${ }^{5}$ e foram lidos todos os artigos que tinham os livros didáticos como objeto de análise. O I EPEA, realizado em 2001, teve 78 trabalhos divulgados nos anais do evento, entre os quais nenhum tem o livro didático como objeto principal de estudo. Nos anais daquele EPEA, há quatro trabalhos referentes a materiais didáticos e em um deles o livro didático é analisado ao lado de outros materiais impressos. Nesse trabalho são analisadas as concepções de ser humano, de natureza e da relação ser humano-natureza em diferentes materiais didáticos. Os resultados apontam para a predominância da visão de que o ser humano é espoliador e destruidor da natureza, e esta, por sua vez, é apenas um depósito de recursos para a sociedade (CAVALARI, CAMPOS e CARVALHO, 2001).

Nos anais da segunda edição do EPEA, realizada em 2003, foram publicados 71 trabalhos, entre os quais apenas um investiga o livro didático ao lado de outros materiais de educação ambiental. Nesse trabalho, elaborado por Manzochi (2003), é feito um perfil da produção de materiais de educação ambiental no Brasil no período de 1985 a 1995 . A autora partiu do mesmo banco de dados utilizado pela referida publicação sobre materiais impressos em educação ambiental, com oitocentos e oitenta materiais registrados, dos quais apenas vinte $(2 \%)$ eram livros didáticos.

Em 2005 foi realizada a terceira edição do encontro, que teve 72 trabalhos publicados em seus anais, dos quais dois se referiam aos livros didáticos. Um deles analisa o tema biodiversidade nos livros didáticos de ciências do Ensino Fundamental (DINIZ e TOMAZELLO, 2005). As autoras verificaram que, de maneira geral, o tema biodiversidade é pouco abordado pelos autores dos livros didáticos e que, quando o são, tais abordagens destacam os prejuízos para o ser humano com a perda da biodiversidade, pautando o foco da discussão por uma ética antropocêntrica, entendendo os animais e as plantas, além do meio físico, como elementos à disposição do ser humano para servirem como recursos econômicos, alimentos, remédios etc. Além disso, essas abordagens são apresentadas como temas complementares, aos finais de capítulo nos livros didáticos, o que pode suscitar que aquele assunto é menos importante.

O outro trabalho publicado no III EPEA, realizado por Ferreira e Wortmann (2005), é desenvolvido na vertente teórica dos estudos culturais e busca analisar o modo como as estratégias para legitimação das orientações oficiais de incluir-se a temática meio ambiente como tema transversal à educação escolar se processam em diferentes produções culturais, tais como textos da mídia e textos de livros didáticos de química. Concluem que os livros didáticos associam o tema meio ambiente ao desenvolvimento tecnológico e reforçam a responsabilidade individual dos sujeitos em ações de preservação ambiental.

A quarta edição do EPEA ocorreu em 2007 e, nos anais do evento, foram publicados 88 trabalhos, sendo dois deles referentes ao livro didático. Um dos trabalhos remete-se à difusão do conhecimento científico sobre meio ambiente nos livros didáticos de história, em que se verifica que os conteúdos ambientais ainda são muito pouco abordados nos livros didáticos desta disciplina (ALMEIDA, 2007).

${ }^{5}$ O V Epea (out-nov/2009) ainda não havia ocorrido quando da realização desta pesquisa. 
Um panorama das pesquisas sobre livro didático ...

O outro trabalho apresentado no IV EPEA verifica os conteúdos ambientais e os pressupostos pedagógicos nos livros didáticos de ciências do primeiro ciclo do Ensino Fundamental, em que se observou que os livros trazem conteúdos relevantes de educação ambiental, mas a importância das ações humanas para a sustentabilidade planetária não é colocada (MORAIS, ZUIN e FREITAS, 2007).

\section{Fonte: Avaliando a educação ambiental no Brasil: materiais impressos}

Em 1996, a editora Gaia, em parceria com a organização não-governamental ambientalista Ecoar, publica o livro "Avaliando a educação ambiental no Brasil: materiais impressos" (TRAJBER e MANZOCHI, 1996). Nesta publicação foi realizado um levantamento de materiais impressos de educação ambiental produzidos no Brasil por diferentes segmentos da sociedade, os quais foram classificados e organizados em um banco de dados.

Ao contrário das outras fontes consultadas, a relação com os livros didáticos está dispersa ao longo do livro. Por isso, fizemos um levantamento de tudo que foi escrito e pontuamos com maior profundidade as abordagens específicas de livro didático.

Entre os materiais impressos de educação ambiental considerados estavam, além de livros didáticos: materiais paradidáticos, de literatura infanto-juvenil, cartilhas, brinquedos/ jogos, folhetos, revistas, jornais, boletins e afins, totalizando oitocentos e oitenta materiais.

$\mathrm{Na}$ análise desses materiais foram verificados diferentes enfoques, relacionados à questão ambiental e à prática educativa, em diferentes capítulos do referido livro por diferentes colaboradores(as) de diferentes campos.

O enfoque linguístico e o discursivo são verificados por Orlandi (1996) em livros didáticos e outros materiais. Com relação à organização textual dos materiais analisados, a autora afirma que não é seguida uma sequência considerada ideal, ou seja, uma organização com história, descrição, efeitos, reflexão e propostas. Quanto ao discurso presente nos textos, os significados para a cidadania são vazios, faltando a implicação de uma relação racional entre o governo, a administração, a ciência e a(o) cidadã(o). Do mesmo modo, o discurso jurídico, instrumento relacionado à cidadania, também está ausente. A oposição entre sociedade e ambiente é recorrente nos materiais. A autora reflete sobre a ausência de um compromisso político e do papel sócio-histórico dos materiais de caráter didático.

Silva (1996), no mesmo sentido do enfoque linguístico e do discurso, faz uma interpretação dos sentidos do discurso que articulam o local e o global na constituição da noção de coletividade. A autora reflete que o discurso ecológico serve para que o sujeito possa se ver e se mostrar como sujeito político. Nos materiais impressos, ele é aquele que está desvinculado da natureza e precisa resgatar seu vínculo. Este resgate, no entanto, é contraditório: o ser humano, quando entendido como parte da natureza, tem um sentido que é universal e atemporal, o que desautoriza interesses restritos a indivíduos e grupos específicos. Sob esta perspectiva, o local e o global nos materiais impressos analisados não assumem a complementaridade, mas o antagonismo.

Outro enfoque analisado foi o da literatura infanto-juvenil em livros didáticos, paradidáticos e de literatura infanto-juvenil, realizado por Coelho e Santana (1996). A análise identifica que há um desajuste entre a linguagem literária e o conteúdo do livro, considerando a respectiva categoria de leitor(a), definida pelos próprios materiais. As autoras enfatizam que, 
nos materiais, o ser humano é tido como destruidor da natureza, por ser ganancioso. É importante ressaltar que, neste sentido, as autoras verificaram que os livros didáticos trazem uma reflexão mais crítica do que os outros materiais, pois chegam a abordar as lacunas dos sistemas políticos e econômicos adotados na sociedade. Por outro lado, em todos os tipos de material analisados, o conhecimento e a informação são considerados os elementos principais no trabalho educativo.

O enfoque pedagógico é analisado por Carvalho et al. (1996), que verificaram os conteúdos referentes à natureza dos conhecimentos, aos valores éticos e estéticos e à participação política das questões ambientais abordadas, e também se atentaram à materialidade das publicações. O principal destaque da análise foi, quanto à natureza dos conhecimentos, a presença de erros conceituais. Os valores éticos trazidos nos materiais enfocam o caráter normativo das proposições em tom imperativo. Sobre os valores estéticos, o verde, nos materiais, é associado à beleza e à humanização de espaços, apesar de em alguns materiais esta valorização estética se dar em torno do utilitarismo da beleza. Com relação à participação política, são poucas as propostas de ação coletiva, enfatizando para a solução dos problemas ambientais as reformas do indivíduo. Porém, os autores ressaltam a riqueza de assuntos tratados, com maior abordagem de conhecimentos ecológicos, de problemas de degradação ambiental e de ações de preservação da natureza.

O enfoque jornalístico também é retratado. Além de investigar os periódicos especificamente, a autora faz uma interpretação das informações retiradas de jornais e revistas que foram transpostas para os livros didáticos. Com isso, algumas implicações para o processo educativo foram identificadas, destacando: a) as informações que remetem a outro momento histórico, já desatualizadas, são colocadas como se representassem o presente ou uma situação permanente, b) ocorre nos livros didáticos uma inserção parcial das notícias, eternizando uma realidade que está fragmentada ou é transitória, c) alguns textos jornalísticos são reproduzidos nos livros didáticos sem a identificação da fonte, sendo utilizados como se fossem saberes construídos pela ciência, e d) as informações jornalísticas são inseridas nos livros didáticos de modo alheio a seus contextos políticos e ideológicos (JOHN, 1996). A autora conclui que "Os jornais devem utilizar seu poder de atualização para transmitir os avanços do conhecimento científico. Mas o livro didático tem a obrigação de trabalhar sobre bases mais sólidas e permanentes do que a imprensa diária" (JOHN, 1996, p. 172).

Destaca-se que, no livro "Analisando a educação ambiental no Brasil: materiais impressos" (TRAJBER e MANZOCHI, 1996), cada um dos enfoques analisados levanta proposições para a elaboração de materiais impressos de educação ambiental no que se refere aos diferentes olhares colocados no livro, acima resumidos.

\section{Outras fontes}

Além das três fontes anteriormente abordadas, foi feito um levantamento complementar, que localizou investigações que relacionam a educação ambiental com o livro didático em outras fontes, como periódicos, bibliotecas, anais de evento e outras revisões similares a esta. Foi considerado um levantamento não sistemático, pois conforme foram sendo encontradas investigações de interesse a este artigo, essas foram sendo incorporadas ao conjunto que compõe este trabalho, embora não façam parte de nenhum dos acervos que foram verificados, 
Um panorama das pesquisas sobre livro didático ...

como os anais do EPEA ou o banco da Capes. Neste levantamento, o critério de seleção de trabalhos foi a referência explícita à educação ambiental e ao livro didático conjuntamente.

Em 1984, Keim (1984 apud LEÃO, 2003) verifica como os livros didáticos de ciências mais adotados na cidade do Rio de Janeiro abordam a relação do ser humano com os demais componentes ambientais. Os resultados apontam para uma inexpressiva preocupação dos livros didáticos de ciências com a questão ambiental. Quando ocorre uma abordagem desta temática, são valorizadas ações predatórias, extrativistas e utilitaristas da sociedade em relação à natureza; além disso, o ser humano não é considerado como parte integrante do ambiente.

Amorim (1997 apud LEÃO, 2003) analisa quatro coleções de livros didáticos de ciências de quinta a oitava série do Ensino Fundamental mais utilizados em Santa Maria (RS), identificando como estas coleções abordam a relação do ser humano com o ambiente. Os resultados indicam que a temática está inserida no currículo, mas de forma a fazer os(as) estudantes memorizarem termos e conceitos para as provas e avaliações escolares. A visão trazida nestas coleções enfatiza o papel do ser humano como destruidor da natureza.

Uma outra investigação realizada analisa as imagens de ecossistemas em livros didáticos de ciências de quinta a oitava séries do Ensino Fundamental, verificando as implicações das mesmas nos processos de educação ambiental. Os resultados indicam que há uma visão estereotipada do conceito de ecossistema, no qual o ser humano nunca está inserido, inclusive em ambientes urbanos, favorecendo uma interpretação de que a harmonia do ambiente natural só é possível longe da presença humana (MENDONÇA FILHO e TOMAZELLO, 2002).

Martins e Guimarães (2002) verificam as concepções de natureza trazidas em 67 livros didáticos de ciências do primeiro ciclo do Ensino Fundamental, aprovados no Programa Nacional do Livro Didático de 2000/2001. Concluem que os mesmos trazem o ser humano como dominador da natureza e reduzem a educação ambiental a ensino de conceitos ecológicos.

Pizzato (2003) faz um levantamento de como os temas ambientais são abordados na disciplina de química por meio dos livros didáticos e de professores(as) de química do Ensino Médio e de estudantes de licenciatura em química. Os resultados mostram que os livros didáticos apresentam uma visão antropocêntrica da natureza e não colocam propostas que desenvolvam ações e comportamentos em defesa do ambiente. A pesquisa indicou ainda uma forte influência dos livros didáticos na formação da opinião dos(as) professores(as), que apresentam visões semelhantes.

Cinqüetti (2004) faz uma análise comparativa do tema dos resíduos sólidos em recursos didáticos dirigidos à (ou assimiláveis pela) faixa etária das séries iniciais do Ensino Fundamental. Entre estes recursos, estão livros paradidáticos, revistas e livros didáticos de ciências e língua portuguesa. Os resultados indicam que, na maioria dos livros didáticos (e também dos demais recursos), o aumento da quantidade de resíduo gerado é abordado; no entanto apontam apenas soluções de ordem tecnológica como alternativa para a questão, especialmente a reciclagem. O consumismo não foi colocado em discussão, sendo entendido como inquestionável. A autora verificou também que há grande disparidade quanto ao tempo de degradação dos materiais no ambiente apresentado pelos diferentes livros didáticos, além de outros erros conceituais.

A outra fonte para a verificação de pesquisas envolvendo educação ambiental e livros didáticos utilizada foi uma dissertação de mestrado sobre o estado da arte da produção científica em educação ambiental no estado de São Paulo no período de 1989 a 2000. Nessa dissertação a autora buscou teses e dissertações cujo descritor ou palavra-chave fosse "educa- 
Marpica, N. S.; Logarezzi, A. J. M.

ção ambiental" e que tivessem sido apresentadas nas universidades públicas paulistas (USP, Unicamp e Unesp - campus de Rio Claro). Ao todo foram encontradas cinco investigações sobre recursos didáticos, mas nenhuma sobre livro didático especificamente (NEVES, 2002).

\section{Considerações finais}

De forma geral, este panorama das pesquisas realizadas permitiu verificar que o livro didático está presente nas investigações ligadas à educação ambiental, contudo de forma um pouco tímida. Ao se verificar quantitativamente a presença de investigações ligadas aos livros didáticos e à educação ambiental, tem-se um percentual bastante baixo. Por exemplo, no banco de dissertações e teses da Capes, foram encontradas dez investigações sobre a temática, enquanto que, ao se buscarem, no mesmo local, investigações somente sobre educação ambiental, foram encontrados 1.905 trabalhos, ou seja, cerca de 0,5\% das dissertações e teses sobre educação ambiental presentes no banco da Capes olham para os livros didáticos.

A quantidade de trabalhos apresentados nas quatro edições do EPEA reforça esta interpretação. Ao todo, foram apresentados 309 trabalhos, dos quais apenas seis remetiam-se aos livros didáticos, isto é, cerca de $2 \%$ do total.

No entanto, muitas vezes quantidade e qualidade não estão diretamente associadas. Nesse sentido, o livro "Analisando a educação ambiental no Brasil: materiais impressos" é um exemplo, na medida em que uma só publicação reúne diferentes enfoques da educação ambiental nos livros didáticos, ao lado de outros materiais de apoio ao processo de educação ambiental. Mas, ainda assim, os livros didáticos presentes na amostra analisada deste material referem-se especificamente à disciplina de ciências (TRAJBER e MANZOCHI, 1996).

A abrangência das pesquisas com relação às disciplinas analisadas é um outro elemento que merece atenção. Apesar das orientações do PCN quanto à transversalidade, dos debates no campo da educação ambiental enfatizarem a interdisciplinaridade e a inclusão de conteúdos para além de conceitos ecológicos, as investigações, em sua maioria, remetem-se aos livros didáticos de geografia ou de disciplina ligada às ciências naturais. Verificou-se que livros didáticos de história tiveram a atenção de algumas pesquisas e, com um pouco menos de ênfase, também os de língua portuguesa; entretanto, nenhuma pesquisa analisou livros didáticos de matemática.

Merece destaque o fato de que nenhuma investigação teve por objetivo estudar a transversalidade de um dado conjunto de livros didáticos em relação a questões ambientais. Esse resultado serviu de justificativa para o projeto de pesquisa da dissertação da qual este artigo faz parte.

Os temas das pesquisas também se repetiram em alguns casos, ora tratando de conceitos ecológicos, como biodiversidade e ecossistemas, ora verificando a relação ser humanonatureza. Conceitos também relevantes para a compreensão da problemática ambiental e para a atuação frente a seus desafios, como os associados a conflitos ambientais, por exemplo, não receberam atenção das pesquisas realizadas.

Ainda no sentido de analisar as lacunas encontradas nas pesquisas, foram encontradas apenas duas investigações que olharam o contexto de uso dos livros didáticos (GROSSI, 2004; PIZZATO, 2003), as demais se limitam ao que está impresso nas páginas dos livros 
didáticos. Sabe-se que o que está impresso nos livros didáticos não é necessariamente o que será ensinado ao(à) estudante. A mediação do(a) educador(a) é o que deve direcionar de que forma o livro será utilizado. Um livro didático ruim pode resultar em uma boa aula e viceversa, de acordo com a condução do(a) educador(a). Por isso, conhecimentos sobre o livro didático para além de suas páginas, como os usos que educadores(as) fazem dele e suas principais necessidades frente a um material de apoio, são importantes de serem construídos para se pensar os caminhos a serem percorridos para que o livro didático seja, de fato, instrumento de apoio à educação ambiental escolar.

Um elemento positivo é o fato de que não ocorre, nas investigações consultadas, uma centralização regional das mesmas, ao contrário do processo de produção dos livros didáticos, que está altamente centralizado na cidade de São Paulo. Esta centralização da produção dos livros se reflete em seus conteúdos, desempenhando um papel importante na marginalização de certos contextos regionais brasileiros.

Os resultados e as conclusões trazidos pelas diferentes investigações são bastante semelhantes, em que as críticas negativas superam os elogios. Por outro lado, verifica-se que as pesquisas mais antigas, quando comparadas com as mais atuais, trazem comentários diferentes. A pesquisa de Keim (1984 apud LEÃO, 2003), por exemplo, indica a pouca presença dos temas ambientais nos livros didáticos de ciências, enquanto que Ribeiro (2006), em um momento histórico mais recente, já ressalta que os livros didáticos estão comprometidos com a abordagem dos mesmos.

A concepção de natureza e a da relação ser humano-natureza foram verificadas por grande parte das pesquisas e se mostraram ora de modo pragmático, em que a natureza é um recurso, ora de forma conservacionista, sendo o ser humano o grande vilão. Porém, a contextualização histórica desta relação não foi constatada pelas investigações. Inclusive as investigações mais antigas, como a de Keim (1984 apud LEÃO, 2003) e a de Fracalanza (1992), também verificavam a concepção de natureza e sua relação com a sociedade e chegaram a estas mesmas conclusões.

Outro elemento que apareceu na maioria das investigações foi o aspecto atitudinal proposto pelos livros didáticos frente às questões ambientais, o qual, ou não era abordado pelos trabalhos ou recebia desses proposições normativas, individuais ou pontuais. Propostas de ação de caráter coletivo e de organização social não foram encontradas nos livros didáticos pelas pesquisas aqui levantadas.

No geral, as investigações verificadas mostraram muitas críticas negativas ao livro didático como uma ferramenta para a educação ambiental. Mas, ainda assim, ao que nos parece, as investigações ainda não deram conta de fazer um panorama suficientemente amplo do livro didático no contexto da educação ambiental escolar. As semelhanças entre temas e disciplinas abordados revelam que as investigações não estão encadeadas, ou seja, não há uma perspectiva de superação do conhecimento construído ou, ainda, uma pesquisa não utiliza os resultados de outra como ponto de partida. Isto talvez se dê pela pouca sistematização do que se tem produzido.

Apesar das críticas constatadas pelas pesquisas acerca dos livros didáticos na abordagem das questões ambientais, não foram encontradas produções de caráter propositivo ao uso e à produção de livros didáticos, ou seja, se as falhas e lacunas dos livros didáticos são conhecidas, é importante que se faça uso desse conhecimento para se propor e sugerir materiais de 
Marpica, N. S.; Logarezzi, A. J. M.

melhor qualidade, exercendo a produção acadêmica o papel de ir além de denúncias e constatações. As proposições são feitas em caráter secundário nas investigações em geral, pois estão sempre acompanhadas de análises específicas dos livros didáticos a que se referem, onde as investigações realizadas anteriormente por outros(as) autores(as) acabam não sendo um ponto de partida para o desenvolvimento de novas propostas, enfatizando novamente o caráter isolado das investigações.

Ainda que bastante criticado pelas investigações quando utilizado como ferramenta de apoio à educação ambiental crítica, deve-se levar em consideração que o livro didático está muito presente nas salas de aula e que o governo investe muito dinheiro público em sua aquisição e distribuição. Deste modo, não podemos desconsiderá-lo como um material que está no universo escolar e, por isso, ao se pensar a educação ambiental permanente e cotidiana na escola, deve-se pensar no livro didático como um importante material que também participa deste processo.

Neste sentido, Bittencourt (2008) alerta que existe um novo elemento que vem tomando espaço dos livros didáticos em escolas municipais: as apostilas dos sistemas particulares de ensino, cujo currículo é altamente normativo e enfatiza o processo de avaliação. Com este novo contexto de inserção de materiais didáticos na escola, devemos repensar o papel do livro didático e as pesquisas científicas devem melhor se organizar para contribuir para que o livro didático seja, de fato, um material de apoio ao processo de ensino e aprendizagem que promova a incorporação da dimensão ambiental na educação escolar brasileira. 
Um panorama das pesquisas sobre livro didático ...

\section{Referências}

ALMEIDA, J. P. A difusão do conhecimento científico sobre meio ambiente nos livros didáticos de história. In: ENCONTRO DE PESQUISA EM EDUCAÇÃO AMBIENTAL, 4., 2007, Rio Claro. Resumos... Rio Claro: Unesp/IB, 2007. p. 34.

BEZERRA, O. S. Temáticas ambientais nos livros didáticos. 2003. Disponível em: <http://servicos.capes.gov.br/capesdw/resumo.html?idtese=200313124001015038P5>; Acesso em: 27 abr. 2008.

BITTTENCOURT, C. Políticas públicas do livro didático no Brasil: o que temos e o que queremos. In: FÓRUM PERMANENTE DE DESAFIOS DO MAGISTÉRIO: O PROFESSOR E O LIVRO DIDÁTICO, 2008, Campinas. Mesa redonda... Campinas: CORI/Unicamp, 2008.

BRASIL. Lei n. 9.795, de 27 de abril de 1999. Institui a Política Nacional de Educação Ambiental e dá outras providências. Brasília, DF, 1999. Disponível em: <www.senado.gov.br>. Acesso em: 25 abr. 2008.

Ministério da Educação. Secretaria de Educação Fundamental. Coordenação de Educação Ambiental. Parâmetros Curriculares Nacionais. Brasília: Ministério da Educação, 1997.

CARVALHO, I. C. M. Educação ambiental: a formação do sujeito ecológico. São Paulo: Cortez, 2004.

CARVALHO, L. M. et al. Conceitos, valores e participação política. In: TRAJBERG, R.; MANZOCHI, L. H. (Orgs.). Avaliando a educação ambiental no Brasil: materiais impressos. São Paulo: Gaia, 1996. p. 37-47.

CAVALARI, R. M. F.; CAMPOS, M. J. O.; CARVALHO, L. M. Educação ambiental e materiais impressos no Brasil: a relação homem-natureza. In: ENCONTRO DE PESQUISA EM EDUCAÇÃO AMBIENTAL, 1., 2001, Rio Claro. Caderno de Resumos... Rio Claro: Unesp, 2001. p. 34.

CINQUETTI, H. C. S. Lixo, resíduos sólidos e reciclagem: uma análise comparativa de recursos didáticos. Educar em Revista, Curitiba, n. 23, p. 307-333, 2004.

COELHO, N. N.; SANTANA; J. S. L. A educação ambiental na literatura infantil como formadora da consciência de mundo. In: TRAJBERG, R.; MANZOCHI, L. H. (Orgs.). Avaliando a educação ambiental no Brasil: materiais impressos. São Paulo: Gaia, 1996. p. $59-76$.

COUTO, R. S. R. Temática ambiental nos livros didáticos de Ciências de $5^{a}$ série do Ensino Fundamental. 2005. Disponível em: < http://servicos.capes.gov.br/capesdw/ resumo.html?idtese $=20057831018017010 \mathrm{P0}>$ Acesso em: 27 abr. 2008. 
Marpica, N. S.; Logarezzi, A. J. M.

DINIZ, E. M.; TOMAZELLO, M. G. C. Um estudo sobre o tema biodiversidade em livros de ciências do ensino fundamental. In: ENCONTRO DE PESQUISA EM EDUCAÇÃO AMBIENTAL, 3., 2005, Ribeirão Preto. Anais... Ribeirão Preto: USP, 2005. p. 1-15.

FERREIRA, M.; WORTMANN, M. L. Meio ambiente: tema "transversal" na educação escolar em ciências/química. In: ENCONTRO DE PESQUISA EM EDUCAÇÃO AMBIENTAL, 3., 2005, Ribeirão Preto. Anais... Ribeirão Preto: USP, 2005. 1 cd-rom.

FRACALANZA, D. C. Crise ambiental e ensino de ecologia: o conflito na relação homem-mundo natural. 1992. 318f. Tese (Doutorado em Educação) - Faculdade de Educação, Universidade Estadual de Campinas, Campinas, 1992.

FREIRE, P. Pedagogia do oprimido. 24. ed. São Paulo: Paz e Terra, 1987.

GROSSI, F. M. C. Educação ambiental e o livro didático no ensino fundamental. 2004. 168f. Dissertação (Mestrado em Extensão Rural) - Universidade Federal de Viçosa, Viçosa, 2004.

GUIMARÃES, M. Educação ambiental crítica. In: LAYRARGUES, P. P. (Coord.). Identidades da educação ambiental brasileira. Brasília: Ministério do Meio Ambiente, 2004. p. 25-34.

JOHN, L. A imprensa "especializada": um papel ainda incerto na educação ambiental. In: TRAJBERG, R.; MANZOCHI, L. H. Avaliando a educação ambiental no Brasil: materiais impressos. São Paulo: Gaia, 1996. p. 153-172.

LEÃO, F. B. F. O que avaliam as avaliações de livros didáticos de ciências? $1^{a}$ a $4^{a}$ séries do Programa Nacional de Livros Didáticos. 2003. 218f. Dissertação (Mestrado em Educação) - Faculdade de Educação, Universidade Estadual de Campinas, Campinas, 2003.

LIMA, G. F. C. Educação ambiental crítica: do socioambientalismo às sociedades sustentáveis. Ciclo de Cursos de Educação Ambiental - Ano 4. São Paulo: Secretaria de Estado do Meio Ambiente, Coordenadoria de Planejamento Ambiental Estratégico e Educação Ambiental, Departamento de Educação Ambiental, 2006. Disponível em: $<$ http://www.ambiente.sp.gov.br/ea/adm/admarqs/Gustavo_Lima.pdf.>. Acesso em: 17 maio 2007.

LOUREIRO, C. F. B. Problematizando conceitos: contribuição à práxis em educação ambiental. In: ___ _ LAYRARGUES, P. P.; CASTRO, R. C. (Orgs.). Pensamento complexo, dialética e educação ambiental. São Paulo: Cortez, 2006. p. 104-161.

. Complexidade e dialética: contribuições à praxis política e emancipatória em educação ambiental. Educação e Sociedade, Campinas, v. 26, n. 93, p. 1473-1494, 2005.

MANZOCHI, L. H. Perfil da produção de materiais de educação ambiental no Brasil. In: ENCONTRO DE PESQUISA EM EDUCAÇÃO AMBIENTAL, 2., 2003. São Carlos. Anais... São Carlos: UFSCAR, 2003. p. 73. 
Um panorama das pesquisas sobre livro didático ...

MARPICA, N. S. As questões ambientais nos livros didáticos de diferentes disciplinas da quinta série do ensino fundamental. 2008. 169f. Dissertação (Mestrado em Educação) - Centro de Educação e Ciências Humanas, Universidade Federal de São Carlos, São Carlos, 2008.

MARTINS, E. F.; GUIMARÃES, G. M. A. As concepções de natureza nos livros didáticos de ciências. Ensaio, Belo Horizonte, v. 4, n. 4, p. 1-14, 2002.

MENDONÇA FILHO, J.; TOMAZELLO, M. G. C. As imagens de ecossistemas em livros didáticos de ciências do ensino fundamental e suas implicações para a educação ambiental.

Revista Eletrônica do Mestrado em Educação Ambiental, Porto Alegre, v. 9, p. 152-158, 2002.

MORAIS, F. A.; ZUIN, V. G.; FREITAS, D. A educação ambiental em livros didáticos de $1^{\text {a }}$ a $4^{a}$ séries do Ensino Fundamental. In: ENCONTRO DE PESQUISA EM EDUCAÇÃO AMBIENTAL, 4., 2007, Rio Claro. Resumos... Rio Claro: Unesp/IB, 2007. p. 51.

NEVES, D. A. F. O “estado da arte” em educação ambiental: a produção científica do período de 1989 a 2000 - uma análise das concepções de meio ambiente, educação e educação ambiental em dissertações de três universidades paulistas. 2002. 131f. Dissertação (Mestrado em Ensino de Ciências) - Faculdade de Educação, Universidade de São Paulo, São Paulo, 2002.

ORLANDI, E. P. O discurso da educação ambiental. In: TRAJBERG, R.; MANZOCHI, L. H. (Orgs.). Avaliando a educação ambiental no Brasil: materiais impressos. São Paulo: Gaia, 1996. p. 37-47.

PEGORARO, J. L. Educação ambiental: a temática da flora, da fauna e dos ambientes naturais (expressões da biodiversidade) a partir da educação formal. 1998. Disponível em: <http://servicos.capes.gov.br/capesdw/resumo.html?idtese=19989833002037014P1>. Acesso em: 27 abr. 2008.

PIZZATO, M. C. Temas ambientais na química do ensino médio: visões de professores, licenciados e livros didáticos. 2003. 157f. Dissertação (Mestrado em Ensino de Ciências) - Faculdade de Educação, Universidade de São Paulo, São Paulo, 2003.

RIBEIRO, M. W. Os conteúdos ambientais em livros didáticos de geografia de $1^{\circ}$ e $2^{\circ}$ ciclos no ensino fundamental. 2006. 125 f. Dissertação (Mestrado em Educação) Faculdade de Educação, Universidade Federal do Paraná, Curitiba, 2006.

SILVA, T. D. O cidadão e a coletividade: as identificações produzidas no discurso da educação ambiental. In: TRAJBERG, R.; MANZOCHI, L. H. (Orgs.). Avaliando a educação ambiental no Brasil: materiais impressos. São Paulo: Gaia, 1996. p. 47-58. 
Marpica, N. S.; Logarezzi, A. J. M.

SOARES, A. A. R. Temáticas ambiental e do trabalho nos livros didáticos de História de $5^{\text {a }}$ a $8^{\text {a }}$ séries do Ensino Fundamental: rede municipal do Rio de Janeiro. 2005.

Disponível em: <http://servicos.capes.gov.br/capesdw/

resumo.html idtese $=20055231018017010$ P0 > . Acesso em: 27 abr. 2008.

SORRENTINO, M. et al. Educação ambiental como política pública. Educação e Pesquisa, São Paulo, v. 31, n. 2, p. 285-299, 2005.

TOZONI-REIS, M. F. C. Educação ambiental: natureza, razão e história. Campinas: Editores Associados, 2004.

TRAJBER, R.; MANZOCHI, L. H. Avaliando a educação ambiental no Brasil: materiais impressos. São Paulo: Gaia, 1996.

Artigo recebido em outubro de 2009 e aceito em janeiro de 2010. 